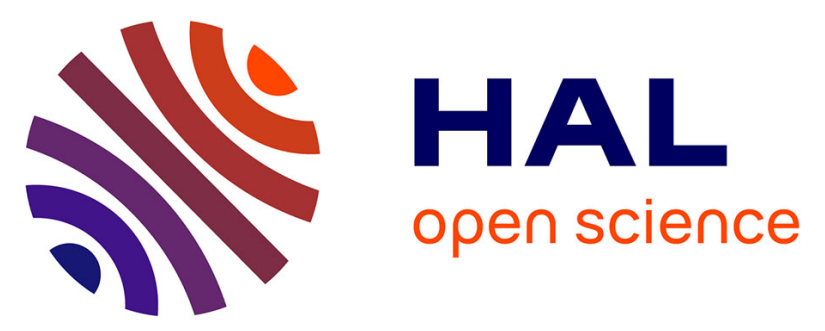

\title{
Electrosynthesis of thin films of polythiophenes containing pyrene groups and flexible spacers, useful in the preparation of graphene polymer composites
}

Bianca Valderrama-García, Israel González-Méndez, Alix Sournia-Saquet, Marine Tassé, Kathleen Moineau-Chane Ching, Ernesto Rivera

\section{To cite this version:}

Bianca Valderrama-García, Israel González-Méndez, Alix Sournia-Saquet, Marine Tassé, Kathleen Moineau-Chane Ching, et al.. Electrosynthesis of thin films of polythiophenes containing pyrene groups and flexible spacers, useful in the preparation of graphene polymer composites. MRS Advances, 2019, 4 (59-60), pp.3233-3242. 10.1557/adv.2019.410 . hal-02345035

\section{HAL Id: hal-02345035 \\ https://hal.science/hal-02345035}

Submitted on 23 Oct 2020

HAL is a multi-disciplinary open access archive for the deposit and dissemination of scientific research documents, whether they are published or not. The documents may come from teaching and research institutions in France or abroad, or from public or private research centers.
L'archive ouverte pluridisciplinaire HAL, est destinée au dépôt et à la diffusion de documents scientifiques de niveau recherche, publiés ou non, émanant des établissements d'enseignement et de recherche français ou étrangers, des laboratoires publics ou privés. 


\section{R S Advances}

\section{ELECTROSYNTHESIS OF THIN FILMS OF POLYTHIOPHENES CONTAINING PYRENE GROUPS AND FLEXIBLE SPACERS, USEFUL IN THE PREPARATION OF GRAPHENE POLYMER COMPOSITES}

\begin{tabular}{|r|l|}
\hline Journal: & MRS Advances \\
\hline Manuscript ID & MRSAdv-2019-IMRC-2097.R1 \\
\hline Manuscript Type: & Regular Article \\
\hline Date Submitted by the \\
Author: & 11 -Oct-2019 \\
\hline Complete List of Authors: & $\begin{array}{l}\text { Valderrama-Garcia, Bianca; UNAM } \\
\text { González-Méndez, Israel; UNAM } \\
\text { sournia-Saquet, Alix; Laboratoire de Chimie de Coordination } \\
\text { Tasse, Marine; Laboratoire de Chimie de Coordination } \\
\text { Moineau Chane-Ching, Kathleen; Laboratoire de Chimie de Coordination } \\
\text { Rivera, Ernesto; Universidad Nacional Autonoma de Mexico Instituto de } \\
\text { Investigaciones en Materiales }\end{array}$ \\
\hline Keywords: & \begin{tabular}{l} 
graphene, polymer, composite \\
\hline
\end{tabular} \\
\hline
\end{tabular}




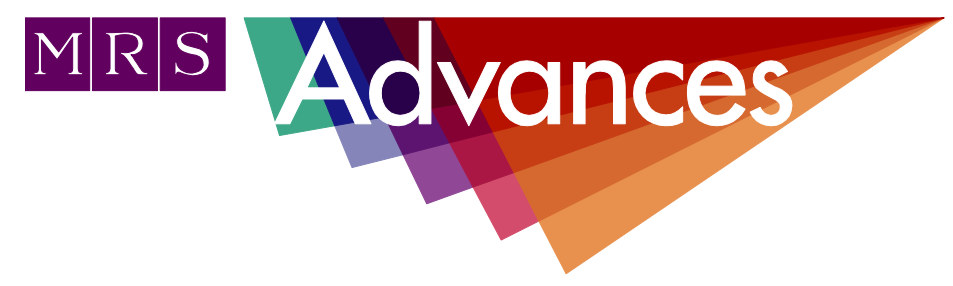

\section{Electrosynthesis of thin films of polythiophenes containing pyrene groups and flexible spacers, useful in the preparation of graphene polymer composites}

Bianca X. Valderrama-García ${ }^{1,2}$, Israel González-Méndez, ${ }^{1}$ Alix Sournia-Saquet ${ }^{2,3}$, Marine Tasse $^{2,3}$, Kathleen I. Moineau-Chane Ching ${ }^{2,3^{*}}$ and Ernesto Rivera ${ }^{{ }^{*}}$

1) Instituto de Investigaciones en Materiales, Universidad Nacional Autónoma de México, Circuito Exterior Ciudad Universitaria C.P. 04510, Ciudad de México, México.

${ }^{2)}$ CNRS; LCC (Laboratoire de Chimie de Coordination); 205, route de Narbonne, 31077 Toulouse, France

3)Université de Toulouse; UPS, INP; LCC; 31077 Toulouse, France

*kathleen.chane@1cc-toulouse.fr (K. M. C.); Tel.: +33 561333133

* riverage@unam.mx (E.R.), Tel.: +52 5556224733

ABSTRACT

Thin polythiophene films were prepared by electrodeposition, using two novel thiophene monomers containing a pyrene unit linked via a flexible spacer. The obtained polymers have a suitable architecture for the further preparation of polymer composites with graphene via $\pi-\pi$ interactions. Physicochemical characterization of the precursor polymers demonstrated that the resulting films are made of homogeneous electroactive polythiophene with pendant pyrene units regularly located on the polymer surface. These compounds are highly emissive and easily form excimers as other high pyrene content polymers. The polymer emission can be drastically quenched by the interaction with graphene after dipping the film into an aqueous suspension of reduced graphite oxide. The presence of aggregated graphene onto pyrene rich content areas by non-covalent interactions has been confirmed by AFM analysis. This kind of polythiophene/pyrene thin films showed to be a good matrix for the elaboration of fluorescent polymer composites. 


\section{INTRODUCTION}

Nowadays, the study of the reactivity and modification of carbon allotropes, particularly graphene, became one of the most promising research topics in nanoscience. Graphene has attracted the attention of many scientist working on this area due to its unique chemical, mechanical, electrical, and thermal properties [1,2]. Graphene exhibits remarkable properties that make it the best prospect for potential applications in organic electronics and in the elaboration of novel optoelectronic devices [3,4], electrodes [5], supercapacitors [6], new sensors [7], high performance biomedical materials [8] and new catalysts [9] among others.

Graphene can be prepared by different methods such as mechanical exfoliation [2], graphite oxidation [10], thermal deposition [11,12], and liquid-phase exfoliation of graphite [13-16]. Nevertheless, recently the Hummers oxidation-reduction method demonstrated to be very efficient and has been extensively used to prepare graphene in large scale. The interaction of graphene with donor and acceptor molecules can be exploited to tune its electronic properties via charge-transfer [17-19]. Many polycyclic aromatic compounds tend to interact with graphene, allowing a non-covalent functionalization of this highly conjugated material [20,21] and other related carbon allotropes, such as single-wall carbon nanotubes. Graphene easily form stable noncovalent bonds with conjugated organic molecules by $\pi-\pi$ stacking and Van der Waals interactions [22-26], which causes a quenching of the emission of these chromophores in the electronic excited state, due to a photoinduced electron transfer [27-30].

On the other hand, fluorescence quenching of pyrene [31] and porphyrin [32, 33 ] by graphene has been investigated and recently reported in the litterature, however, the quenching mechanism has not been completely clarified. Theoretical simulations proved that a wide range energy transfer occurs in the fluorescence quenching of an emitter interacting with graphene [34,35]. Therefore, fluorescence quenching by graphene has been efficiently employed for the selective detection of certain biomolecules [36] and other analogue compounds [37-39]. Moreover, fluorescence quenching of other $\pi$-conjugated polymers, and emissive dyes such as 1-pyrenebutyric acid by graphene has been also explored [40-46].

It is very well known that pyrene is a highly fluorescent compound extensively used for polymer labeling because of it easily forms excimers. In addition, pyrene shows a long singlet lifetime that facilitates the study of the photophysical processes [47]. An excimer emission takes place when a pyrene in the excited state interacts with another pyrene in the ground state, after which a photon is delocalized along the conjugate, thereby provoking a significant change in the fluorescence spectrum. We have reported the synthesis and characterization of many series of conjugated polymers and oligomers containing pyrene moieties. Our investigations mainly focused on the effect of the internal stacking of pyrene units on the optical and photophysical properties [48-51]. These polymers can be prepared either chemically or electrochemically, but the electropolymerization showed advantages over other synthetic approaches, because no catalyst is necessary and a doped polymer film is deposited on the electrode surface, so that it is possible to characterize in situ and control of thickness of the obtained polymer film [52].

Given the importance of graphene chemistry, firstly we decided to explore whether this conjugated compound can form composites with these pyrene containing polythiophenes, which this can be monitored by quenching of the excited pyrene in thin films in aqueous suspension. Secondly, we investigated the fluorescence quenching of the prepared series of polythiophenes having pyrene units in the presence of graphene 
(Figure 1, vide infra) [53]. These polymers showed interesting optical properties, and we studied their fluorescence quenching after having been associated with graphene via noncovalent interactions.

\section{EXPERIMENTAL WORK}

\section{$\underline{\text { 2.1 Preparation of reduced graphite oxide (rgo) }}$}

Graphene was prepared from graphite by the Hummers method [54]. Initially, graphite oxide (GO), previously obtained from graphite powder, was treated with hydrazine hydrate $50 \%$ heating at $95^{\circ} \mathrm{C}$ for $24 \mathrm{~h}$ [55]. The resulting solid was separated by filtration and washed many times with deionized water to give pure reduced graphite oxide (rGO).

\subsection{Electrochemistry}

ITO/glass rectangular plates (dimensions $=0.8 \mathrm{~cm} \times 5.0 \mathrm{~cm}$ ), consisting on 100 $\mathrm{nm}$ thickness ITO (25-35 ohms) deposited on glass (1.1 mm thick), were purchased from SOLEMS. The plates were cleaned and degreased by sonication for 15 minutes in $\mathrm{CH}_{2} \mathrm{Cl}_{2}$. Afterwards, they were rinsed with acetone, then with ethanol and allowed to dry at ambient atmosphere in the absence of dust. Cyclic voltammetry measurements were recorded with an Autolab PGSTAT100 potentiostat controlled by GPES 4.09 software (Metrohm France SAS, Villebon Courtaboeuf France). The experiments were achieved at room temperature $(298 \pm 2 \mathrm{~K})$, in a homemade airtight three-electrode cell connected to a vacuum/argon line. The obtained polymers were deposited at a scan rate of $0.1 \mathrm{Vs}^{-1}$ and the electroactive area was about $1.4 \mathrm{~cm}^{2}$. No sooner did the electropolymerization finish, the electrode plates were rinsed by dipping them twice in fresh $\mathrm{CH}_{2} \mathrm{Cl}_{2}$ and then allowed to dry in a test tube at room temperature.

\section{$\underline{2.3 \text { Interaction of the polymer surface with rgo }}$}

rGO (15 mg) was dispersed in distilled water $(30 \mathrm{~mL})$, and the resulting mixture was sonicated for $30 \mathrm{~min}$ at $60^{\circ} \mathrm{C}$, then it was allowed to cool down to room temperature for $30 \mathrm{~min}$. Afterwards, the upper suspension was collected and poured by 5 $\mathrm{mL}$ aliquots in test tubes. The plate of ITO/glass covered by polymer was dipped into the solution either overnight at room temperature, or for 2 minutes at $45^{\circ} \mathrm{C}$, under gentle stirring in order to favor the contact of dispersed graphene with the polymer surface, without releasing the deposited polymer. Then, the plate was withdrawn from the solution and rinsed twice by dipping it in distilled water in order to ensure the entire removal of non-aggregated $\mathrm{rGO}$, then it was allowed to dry at open air.

\subsection{Atomic force microscopy}

Atomic Force Microscopy experiments (SmartsSPM-1000, AIST-NT) were employed to analyze the surface morphology of the obtained deposited films. The topography was measured in tapping mode with a silicon tip of $4 \mathrm{~nm}$-radius curvature. We evaluated the film thickness by measuring the step created by scratching the surface in different points of the film with the intention of getting an average value. 


\section{RESULTS AND DISCUSSION}

\subsection{Electropolymerization of the monomers}

Thiophene monomers having a pyrene moiety in the 3-position of the aromatic ring can be polymerized by chemical or electrochemical methods to produce thin films deposited on ITO or glass substrates. Herein, we present the continuation of our investigation [53] consisting on the electrochemical preparation of homogeneous films of about $100 \mathrm{~nm}$ thickness and the interaction of the obtained polymers e-TPP3 and e-TPP4 with graphene via non-covalent interactions. The structures of the polymers are shown in Figure 1. As we can see, the spacer between the thiophene and the pyrene moiety has an alkyl-ester, where the ester function is separated from the thiophene ring by one carbon and from the pyrene unit by an alkyl chain.

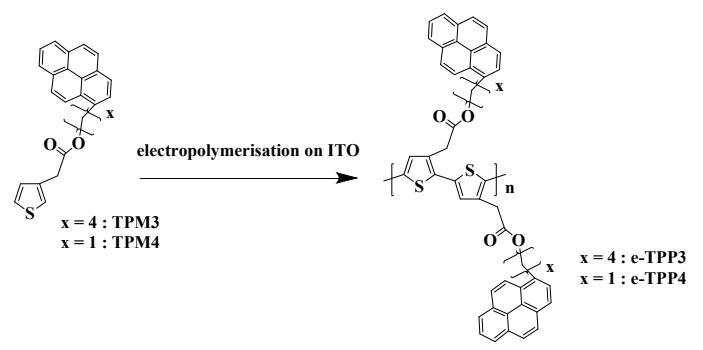

Figure 1. Electropolymerization of TPM3 and TPM4 to obtain the corresponding polythiophenes: e-TPP3 and e-TPP4.

Both monomers show similar electrochemical behavior, exhibiting an oxidation potential peak at 1.4 V/SCE, due to the thiophene ring [53]. The optimum upper voltage to produce a good electroactive polymer was $1.6 \mathrm{~V} / \mathrm{SCE}$. Using a higher maximum value leads to an overoxidation process, with a decreasing current value from one cycle to another, giving rise to a poor quality film (Figure 2).
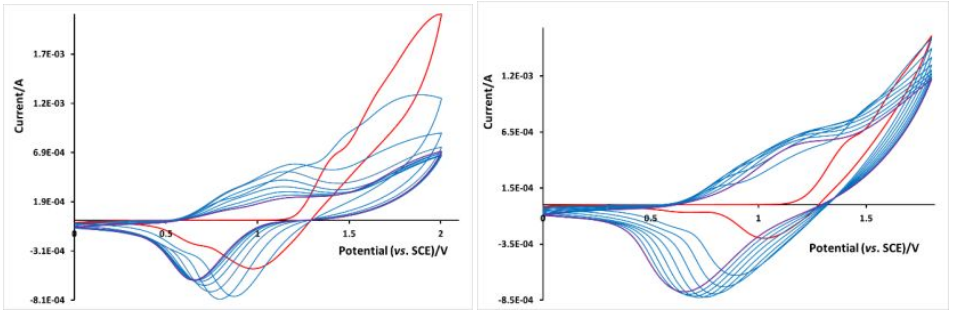

Figure 2. Electrosynthesis of e-TPP3 $1.510^{-3} \mathrm{~mol} \mathrm{~L}^{-1}$ in $\mathrm{CH}_{2} \mathrm{Cl}_{2}+0.1 \mathrm{~mol} \mathrm{~L}^{-1}\left(n-\mathrm{Bu}_{4} \mathrm{~N}\right)\left[\mathrm{PF}_{6}\right]$ using cyclic voltammetry between 0 and (left) 2.0 and (right) $1.8 \mathrm{~V} / \mathrm{SCE}$ on ITO electrode $\left(10\right.$ cycles ). Scan rate $=0.1 \mathrm{~V} \cdot \mathrm{s}^{-1}$. The first cycle is plotted in red, the intermediates in blue, and the $10^{\text {th }}$ in purple.

The growth of the polymer layer onto the electrode showed to be regular up to 1.6 V/SCE (Figure 3), leading after 5 cycles of sweeping to homogeneous deposits, having a thicknesses of around $80 \mathrm{~nm}$ for e-TPP3 and $130 \mathrm{~nm}$ for e-TPP4, as measured by AFM. For each monomer, we formed 10 films under the same conditions. The obtained voltammograms are strictly identical for a given monomer, thereby indicating a noticeable stability of the electrolyte solution. Moreover, the films exhibited good and 
stable electroactivity in $\mathrm{CH}_{2} \mathrm{Cl}_{2}$ (see insets in Fig. 3). Surprisingly, the rigidity of the monomer structure proved to be an advantage to assist the electropolymerization, since the observed currents were twice higher for e-TPP4 than for e-TPP3 from the first electropolymerization cycles. In this case, the polymerization process as well as the films quality are satisfactorily reproducible for each monomer.
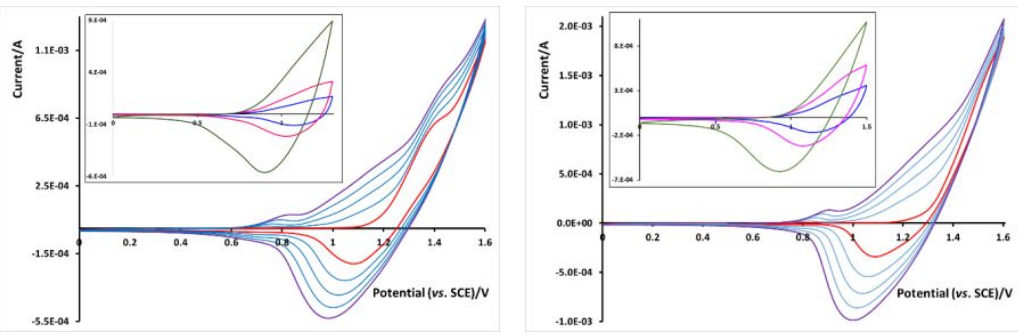

Figure 3. Electrochemical polymerization of TPM3 (left) and TPM4 (right) by cyclic voltammetry between 0 and 1.6 V/SCE in $1.510^{-3} \mathrm{~mol} \mathrm{~L}^{-1}$ monomer $+0.1 \mathrm{~mol} \mathrm{~L}^{-1}\left(n-\mathrm{Bu}_{4} \mathrm{~N}\right)\left[\mathrm{PF}_{6}\right] \mathrm{CH}_{2} \mathrm{Cl}_{2}$ solution onto ITO electrode. Scan rate $=0.1$ $\mathrm{V} \cdot \mathrm{s}^{-1}$. Red $=1^{\text {st }}$ cycle, blue $=2^{\text {nd }}-4^{\text {th }}$ cycles, purple: $5^{\text {th }}$ cycle. Inserts $=$ electroactivity in $\mathrm{CH}_{2} \mathrm{Cl}_{2}$ of the formed films at 50 (blue), 100 (red), $500 \mathrm{mV} / \mathrm{s}$ (green).

\subsection{Optical properties of the obtained polymers}

Figure 4 shows the absorption and emission spectra of e-TPP3 and e-TPP4 films electrodeposited on ITO. Because of the film thickness, e-TPP4 polymer exhibits higher absorption and emission intensity than e-TPP3, at least twice. Both polymers display absorption bands in the range between $350-500 \mathrm{~nm}$. The lower value is restricted by the substrate absorbance while the upper value is extended, due to the homogeneity of the deposited polythiophene film.

Monomer TPM3 exhibits a $\lambda \max$ at $345 \mathrm{~nm}$, due to the typical $\mathrm{S}_{0} \rightarrow \mathrm{S}_{2}$ transition of pyrene. In the corresponding polymer e-TPP 3 this band is bathochromically shifted and broadened, showing $\lambda \max$ at $380 \mathrm{~nm}$ followed by a shoulder at $450 \mathrm{~nm}$. The onset of the absorption band is estimated to be at $500 \mathrm{~nm}$, related to an electronic band gap of $2.4 \mathrm{eV}$; this value corresponds to short oligothiophene chains [56, 57]. The fluorescence spectra of the prepared polymers do not exhibit any well-structured "monomer" emission band at 390-410 $\mathrm{nm}$ as expected for free pyrene molecules, but only an intense broad emission band centered at $\lambda=540 \mathrm{~nm}$, arising from an energy transfer from the pyrene units to the oligothiophene in thin films, since usually pyrene excimers appear at $480 \mathrm{~nm}$ [47]. e-TPP4 behaves similarly to its analogue but shows broader absorption and emission bands.

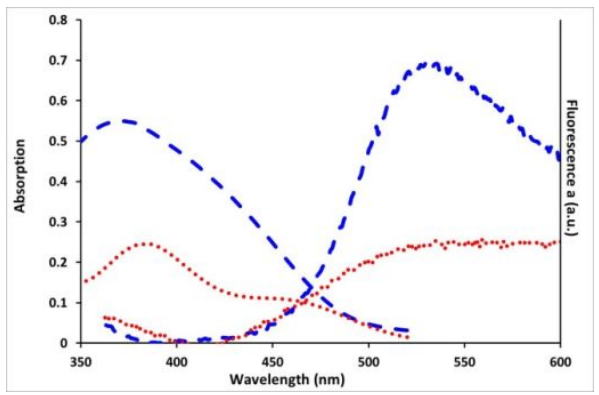


Figure 4. Absorbance and emission $(\lambda e x c=340 \mathrm{~nm})$ spectra in thin film of e-TPP3 (red) and e-TPP4 (blue) deposited by electropolymerization on ITO/glass.

\subsection{Surface analysis of the polymer films}

The topography of the electrodeposited films was investigated by Atomic Force Microscopy (AFM). Both films have a homogeneous aspect, showing small grains regularly dispersed on the surface, where e-TPP4 is slightly rougher than e-TPP3. In Figure 5 (bottom), we can observe that these grains have almost the same size for a given polymer, with an average diameter of $0.05 \mu \mathrm{m}$ for e-TPP3 and $0.1 \mu \mathrm{m}$ for e-TPP4. As a result, the measured arithmetic roughness $(\mathrm{Ra})$ is smaller for e-TPP3 $(4.5 \mu \mathrm{m})$ than for eTPP4 (10 $\mu \mathrm{m})$.
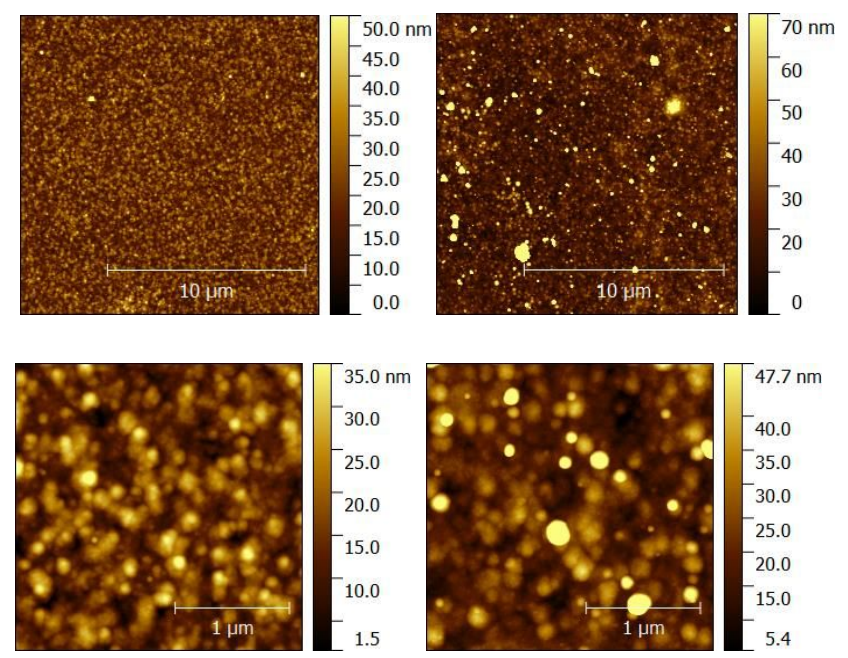

Figure 5. AFM surface topography of e-TPP3 (left) and e-TPP4 (right) thin films deposited by cyclic voltammetry on ITO/glass electrodes. Examined areas: $15 \times 15 \mu \mathrm{m}$ (top), $2.5 \mu \mathrm{m}$ (bottom).

\subsection{Interaction with Graphene}

Pyrene was employed as anchoring group and fluorescent label in this work because of its strong $\pi-\pi$ interactions with other conjugated molecules and its remarkable photophysical properties like high quantum yield, long singlet lifetime, and sensitivity to the polarity of the environment. That is why it has been successfully used for the detection of oxygen [58], trinitrotoluene [59], and other related explosives [60]. Herein, we aim to demonstrate the ability of the prepared polymer films to form composites with graphene, employing the fluorescence quenching of pyrene to detect the stacking. For this purpose, we decided to use the most emissive polymer e-TPP4 as fluorescent probe.

e-TPP4 films contain polythiophene chains with free pyrene units on the surface as it was confirmed by the specific fluorescence features of the emission spectrum. To demonstrate the potentiality of these polymers to form composites through non covalent interactions, we used reduced graphene oxide (rGO) because it is a very good linker that undergoes $\pi-\pi$ stacking with pyrene [61], which can be monitored by fluorescence quenching. Usually, the interaction between both species is assisted by ultrasonic treatment of the mixture, but it is not appropriate here, since in some cases undergoes severe delamination of the film from the ITO surface. To overcome this 
problem, we used the dipping technique in a saturated aqueous solution of rGO, with a concentration about $4.74 \mathrm{mg} / \mathrm{mL}$ [62].

After dipping the polymer probes into the solution (see Experimental work), the fluorescence spectra of the films were recorded. The corresponding absorption and emission spectra are shown in Figure 6. We can notice that the interaction of the pyrene containing polythiophene with rGO solutions gives rise to a quenching effect at different extent depending on the employed conditions. At room temperature, the interaction of rGO with pyrene is very weak, which can be seen by a minor decrease in the emission intensity, even after one night of dipping. Working at slightly higher temperature, i.e. $45^{\circ} \mathrm{C}$, we can detect a significant interaction between rGO and pyrene, which causes a substantial emission quenching (Figure 6).

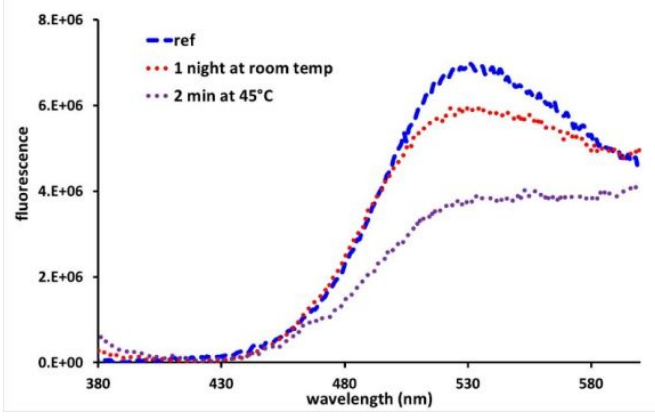

Figure 6. Fluorescence spectra recorded on e-TPP4 thin films deposited on ITO/glass by electropolymerization, then being placed in contact with an rGO solution at different temperatures and times.

AFM analysis of the films after dipping did not provide any direct evidence of a significant change on the surface topology: the features previously seen before dipping were observed again, with no specific signs of the presence of graphene. Demonstration of absorbed graphene onto the surface was achieved via "in phase" AFM measurements as shown in Figure 7. This experiment clearly shows a more contrasted image after (right bottom), and before dipping (right top). This reveals the presence of two different components on the film surface, resulting from the interaction of the pyrene containing polythiophene with graphene. Moreover, in the "in phase" cliché of the dipped polymer (right bottom), the location of clear zones (of a few tenth of nanometers diameter) fits well with those of the apparent relief peaks, evidenced by the topology examination (right top), which are due to the presence of adsorbed graphene on pyrene units. Other aromatic compounds can be used to prepare this kind of composites such as porphyrinic systems able to form complexes via $\pi-\pi$ interactions [63].
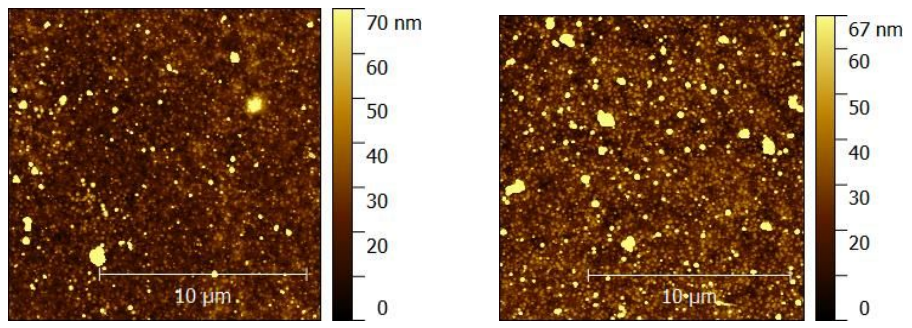

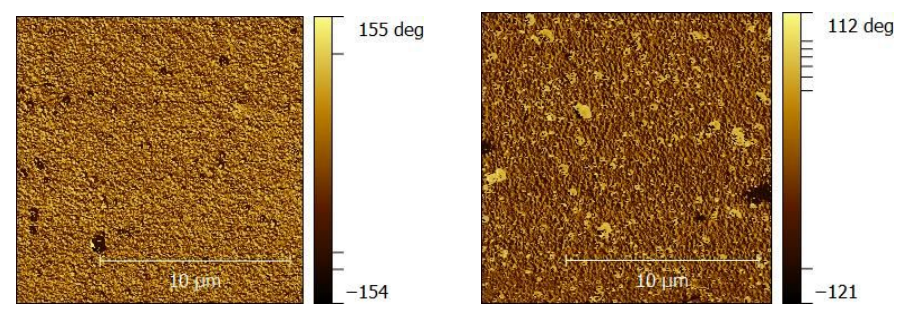

Figure 7. AFM images of e-TPP4 thin films deposited by cyclic voltammetry on ITO/glass electrodes before (left) and after (right) dipping in aqueous saturated $\mathrm{rGO}$ solution at $45^{\circ} \mathrm{C}$ for $2 \mathrm{~min}$. Top: topographic examination. Bottom: phase signal measurement. Examined areas: $15 \times 15 \mu \mathrm{m}$

\section{CONCLUSIONS}

Polythiophenes having pyrene units and flexible alkyl spacers were successfully electrosynthesized and characterized. Thin electroactive polymer films deposited on ITO plates (e-TPP3 and e-TPP4) were prepared. The fluorescence spectra of these polymers show two emission bands: a pyrene monomer emission band at $\lambda=390-410 \mathrm{~nm}$ due to, and a broad excimer emission band at $\lambda=540 \mathrm{~nm}$, resulting from intermolecular pyrenepyrene interactions.

Based on the importance of graphene chemistry and its behavior in the presence of organic chromophores, we demonstrated how the interaction of the pyrene labeled polymer with rGO solutions gives rise to the incorporation of graphene via non covalent interactions under optimal conditions. This can be monitored by the quenching effect of the e-TPP4 polymer emission. At room temperature, the interaction of $\mathrm{rGO}$ with pyrene is quite weak, however, when we work at higher temperature $\left(45^{\circ} \mathrm{C}\right)$, we notice a significant interaction between $\mathrm{rGO}$ and pyrene, which provokes a substantial fluorescence quenching. From these results, we can conclude that these polythiophenes are optimal precursor materials for the obtainment graphene composites via $\pi-\pi$ interactions and the remaining non-associated pyrene units can act as fluorescent probes, making these compounds very useful in the field of organic electronics.

\section{ACKNOWLEDGEMENTS}

Authors thank PAPIIT-DGAPA (Project IN-100316) and CONACyT (Project 253155) and Framework of the French-Mexican International Laboratory (LIALCMMC) supported by CNRS and CONACyT for financial support.

\section{REFERENCES}

[1] A.K. Geim, K.S. Novoselov, Nat. Mater. 6 (2007) 183-191.

[2] K.S. Novoselov, A.K Geim, S.V. Morozov, D. Jiang, Y. Zhang, S.V. Dubonos, I.V. Grigorieva, A.A. Firsov, Science 306 (2004) 666-669.

[3] Y. Xu, Y. Wang, J. Liang, Y. Huang, Y. Ma, X. Wan, Y. Chen, Nano Res. 2 (2009) 343-348.

[4] Z. Yang, X. Shi, J. Yuan, H. Pu, Y. Liu, Appl. Surf. Sci. 257 (2010) 138-142.

[5] X. Wang, J. Wang, H. Cheng, P. Yu, J. Ye, L. Mao, Langmuir 27 (2011) 11180-11186.

[6] F. Li, J. Song, H. Yang, S. Gan, Q. Zhang, D. Han, A. Ivaska, L. Niu, Nanotechnology 20 (2009) 455602.

[7] W. Tu, J. Lei, S. Zhang, H. Ju, Chem. Eur. J. 16 (2010) 10771-10777.

[8] G. Zeng, Y. Xing, J. Gao, Z.Wang, X. Zhang, Langmuir 26 (2010) 15022-15026.

[9] W. Hong, H. Bai, Y. Xu, Z. Yao, Z. Gu, G. Shi, J. Phys. Chem. C 114 (2010) 1822-1826.

[10] D.A. Dikin, S. Stankovich, E.J. Zimney, R.D. Piner, G.H.B. Dommett, G. Evmenenko, S.T. Nguyen, R.S. Ruoff, Nature 448 (2007) 457-460. 
[11] C. Berger, Z. Song, X. Li, X. Wu, N. Brown, C. Naud, D. Mayou, T. Li, J. Hass, A.N. Marchenkov, E.H. Conrad, P.N. First, W.A. de Heer, Science 312 (2006) 1191-1196.

[12] D. Wei, Y. Liu, Y. Wang, H. Zhang, L. Huang, G. Yu, Nano Lett. 9 (2009) 1752-1758.

[13] H. Chen, M.B. Muller, K.J. Gilmore, G.G. Wallace, D. Li, Adv. Mater. 20 (2008) 3557-3561.

[14] X.L. Li, X.R. Wang, L. Zhang, S.W Lee, H.J Dai, Science 319 (2008) 1229-1232.

[15] X. Li, G. Zhang, X. Bai, X. Sun, X. Wang, E. Wang, H. Dai, Nat. Nanotechnol. 3 (2008) $538-$ 542.

[16] M. Choucair, P. Thordarson, J.A. Stride, Nat. Nanotechnol. 4 (2009) 30-33.

[17] B. Das, R. Voggu, C.S. Rout, C.N.R. Rao, Chem. Commun., 41 (2008), 5155-5157.

[18] R. Voggu, B. Das, C.S. Rout, C.N.R. Rao, J. Phys.: Condens. Matter 20 (2008) 472204 (1-5).

[19] K.S. Subrahmanyam, R.Voggu, A. Govindaraj, C.N.R. Rao, Chem. Phys. Lett. 472 (2009) 9698.

[20] K.S. Subrahmanyam, A. Ghosh, A. Gomathi, A. Govindaraj, C.N.R. Rao, Nanosci. Nanotechnol. Lett. 1 (2009) 28-31.

[21] A. Ghosh, K.V. Rao, S.J. George, C.N.R. Rao, Chem. Eur.J. 16 (2010) 2700-2704.

[22] S. Stepanian, V.A. Karachevtsev, A.Y. Glamazda, U. Dettlaff-Weglikowska, L. Mol. Phys. 101 (2003) 2609-2614.

[23] Y.H. Xie, A.K Soh, Mater. Lett. 59 (2005) 971-975.

[24] J.A.A.W. Elemans, R. Van Hameren, R.J.M. Nolte, A.E Rowan, Adv. Mater. 18 (2006) 12511266.

[25] D.M. Guldi, G.M.A. Rahman, F. Zerbetto, M. Prato, Acc. Chem. Res. 38 (2005) 871-878.

[26] H. Murakami, T. Nomura, N. Nakashima, Chem. Phys. Lett. 378 (2003) 481-485.

[27] M. Alvaro, C. Aprile, B. Ferrer, H. Garcia, J. Am. Chem. Soc. 129 (2007) 5647-5655.

[28] D.M. Guldi, A. Rahman, V. Sgobba, C. Ehli, Chem. Soc. Rev. 35 (2006) 471-487.

[29] R. Martin, M. Alvaro, H. Garcia, Curr. Org. Chem. 15 (2011) 1106-1120.

[30] I. Robel, B.A. Bunker, P.V. Kamat, Adv. Mater. 17 (2005) 2458-2463.

[31] M. De Miguel, M. Álvaro, H. García, Langmuir 28 (2012) 2849-2857.

[32] Y. Xu, Z. Liu, X. Zhang, Y. Wang, J. Tian, Y. Huang, Y. Ma, X. Zhang, Y. Chen, Adv. Mater. 21 (2009) 1275-1279.

[33] Y. Xu, L. Zhao, W. Hong, C. Li, G. Shi, J. Am. Chem. Soc. 131 (2009) 13490-13497.

[34] R.S. Swathi, K.L. Sebastian, J. Chem. Phys 129 (2008) 054703.

[35] R.S. Swathi, K.L. Sebastian, J. Chem. Phys 130 (2009) 086101.

[36] C.H. Lu, H.H. Yang, C.L. Zhu, X. Chen, G.N. Chen, Angew. Chem. Int. Ed. 48 (2009) 47854787.

[37] E. Treossi, M. Melucci, A. Liscio, M. Gazzano, P. Samori, V. Palermo, J. Am. Chem. Soc. 131 (2009) 15576-15577.

[38] P.V. Kamat, J. Phys. Chem. Lett. 1 (2010) 520-527.

[39] L. Xie, X. Ling, Y. Fang, J. Zhang, Z. Liu, J. Am. Chem. Soc. 131 (2009) 9980- 9981.

[40] Y. Liu, C.Y. Liu, Appl. Surf. Sci. 257 (2010) 5513-5518.

[41]H. Matte,K.S. Subrahmanyam,K.V. Rao,S.J. George,C.N.R. Rao, Chem. Phys. Lett. 506 (2011) $260-264$.

[42] C.N.R. Rao, K.S. Subrahmanyam, H. Matte, A. Govindaraj, Mod. Phys. Lett. B 25 (2010) 427-451.

[43] J.Q. Tian, H.L. Li, Y.L. Luo, L. Wang, Y.W. Zhang, Y. W., X.P . Sun, Langmuir 27 (2010) 874-877.

[44] Y.B. Wang, D. Kurunthu, G.W. Scott, C.J. Bardeen, J. Phys. Chem. C 114 (2010) 4153-4159.

[45] X.M. Wu, H.Q. Cao, B.J. Li, G. Yin, Nanotechnology 22 (2011) 75202.

[46] X.F. Zhang, Q. Xi, Carbon 49 (2011) 3842-3850.

[47] F.M. Winnik, Chem. Rev. 93 (1993) 587-614.

[48] E. Rivera, M. Belletête, X.X. Zhu, G. Durocher, R. Giasson, Polymer 43 (2002) 5059-5068.

[49] E. Rivera, R. Wang, X.X. Zhu, D. Zargarian, R. Giasson, J. Mol. Catal. 204 (2003) 325-332.

[50] M. Belletête, E. Rivera, R. Giasson, X.X. Zhu, G. Durocher, Synth. Met. 14 (2004) 37-42.

[51] O. Morales-Saavedra, E. Rivera, Polymer 47 (2006) 5330-5337.

[52] K. Yoshino, S. Nakajima, M. Onada, R. Sugimoto, Synth. Met. 28 (1989) 349-357.

[53] B.X. Valderrama-García, K.I Moineau-Chane Ching, E. Rivera, Molecules 21 (2016) 172.

$54]$ W.S. Hummers, R.E. Offeman, J. Am. Chem. Soc. 80 (1958) 1339-1339.

[55] S. Park, J. An, J.R. Potts, A. Velamakanni, S. Murali, R.S. Carbon. 49 (2011) 3019-3023.

[56] R. Berridge, S.P. Wright, P.J. Skabara, A. Dyer, T. Steckler, A.A. Argun, J.R. Reynolds, R. Harrington, W. Clegg, J. Mater. Chem.17 (2007) 225-231.

[57] S. P. Rittmeye1, A. Groß, Beilstein J Nanotechnol. 3 (2012) 909-919.

[58] Y.X. Yuan, H.S. Peng, J.T. Ping, X.H. Wang, F.T. You, Biomed Res Int 11 (2015) 245031.

[59] P. Beyazkilic, A. Yildirim, M. Bayindir, Nanoscale 6 (2014) 15203-9.

[60] X. Sun, Y. Liu, G. Shaw, A. Carrier, S. Dey, J. Zhao, Y. Lei, ACS Appl. Mater. Interfaces 7 (2015) 13189-97.

[61] S. J. Park, S. Kim, T.F. Florence Anjong, S.E. Lee, J. Kim, Carbon 94 (2015) 448-454.

[62] K. Dimitrios, M.M. Stylianakis, E. Stratakis, E. Kymakis, J. Colloid Interface Sci. 430 (2014), 430, 108-112.

[63] S.M. Rojas-Montoya, M. Vonlanthen, P. Porcu, G. Flores-Rojas, A. Ruiu, D. MoralesMorales, E. Rivera. Dalton Transactions 48 (2019), 10435-10447. 